\title{
FIELD TESTS OF EXPANSIVE SOIL EMBANKMENT SLOPE DEFORMATION UNDER THE EFFECT OF THE RAINFALL EVAPORATION CYCLE
}

\author{
WANG, J. D. - GU, T. F. - XU, Y. J. \\ Department of Geology/The Key Laboratory of Continental Dynamics, Northwest University, \\ $X i$ 'an 710069, China \\ Corresponding author \\ e-mail:2685982291@qq.com \\ (Received 24 $4^{\text {th }}$ Oct 2016; accepted 20 $0^{\text {th }}$ Dec 2016)
}

\begin{abstract}
In order to provide the necessarily basic parameters for designing the planned airport project in the An Kang area using expansion soil, a local physical model is being made, in particular to assess fill slope stability and for follow-up testing of the slope deformation under the effect of the rainfall evaporation cycle, and subsequent analysis of the law of evolution and formation mechanism of the slope deformation. The results show the following. (1) There are three stages of rainwater infiltration into newly-built fill slopes, free infiltration, scouring infiltration and erosion stable infiltration. In this experiment, the major rainwater infiltration process is the scouring infiltration stage, leading to the limited depth of infiltration. (2) For a completely uniform fill slope, the development of the deformation is affected by the leading role of the expansion soil deformation; the deformation of the top of the hill mainly shows vertical swell - shrink deformation, but the surface of the slope shows mainly horizontally cumulative deformation. With the increasing depth and rainfall frequency, the deformation rate drastically reduces. (3) The slope deformation is closely related to rainfall and evaporation, and rainfall is the main factor leading to the sharply increased deformation, evaporation is a necessary prerequisite for the development of the deformation. (4) Preventing rainfall and evaporation destruction and deformation of the slope should be commenced from two aspects: first, effectively reduce soil moisture variations of the slope influencing the scope on the surface, and second, prevent slope erosion and scouring by runoff.

Keywords: expansive soil; shallow landslide; physical simulation; affection of atmosphere; artificial embankment
\end{abstract}

\section{Introduction}

Expansive soil is highly plastic clay which, having fractured, shows water swelling and drying shrinkage characteristics and is extremely sensitive to water in particular (Ding et al., 2006). Studies have shown that small changes in water content can cause significant changes in the engineering properties of the expansive soil (Yang and Ding, 2006), whereas under natural environmental conditions, the wetting - drying cycle (precipitation and evaporation occurring alternately) is the main cause of soil moisture changes. Examples of the collapse and instability of slopes caused by climate change are legendary (Yuang et al., 2007). Therefore, the influence of slope deformation and safety caused by changes in reciprocating climatic factors has attracted the attention of domestic and foreign scholars.

Many experimental studies of artificial and natural rainfall have revealed the deformation mechanism and laws of the slope. Chen et al. (2007a) studied the deformation and stability of expansive soil slopes under wetting - drying cycle conditions using the centrifugal modelling test. Tu et al. (2009) analysed the mechanism of the unsaturated soil during rainfall infiltration and rainfall-induced landslide instability. Zhang et al.(2007) analysed the relationship between landslide and rainfall, 
rainfall intensity or rainfall patterns. Chen et al. (2007b) established an expansive soil slope monitoring system in situ in Nanning, Guangxi, and found the laws of the slope with climate change. $\mathrm{Ng}$ et al. (2003) conducted rainfall simulation experiments to assess the interaction mechanism of soil and water under the rainfall infiltration effect. Sammori and Tsuboyama (1991) studied the effects of the transient seepage of a man-made slope and slope stability under various rainfall conditions. Toll (2001) found the intrinsic relationship among landslides and rainfall intensity, and gradient or slope height by analysing landslides caused by artificial rainfall.

In order to provide the necessarily basic parameters for designing the planned airport project using expansion soil as the padding in the An Kang area, we conducted pre-tests on the fill slope deformation characteristics. A physical test model of the expansive soil fill slope in situ was established in the simulated ground, and Hall displacement sensors, a soil moisture sensor, barometer, etc. were used. A series of deformations of the expansive soil fill slope were tested under the effect of the rainfall - evaporation cycle, and then the law of evolution law and the genetic mechanism were analysed. These were significant to the design and construction of the planned airport project.

\section{Test site profile}

The test site is located in Zhu Jiawan village, $\mathrm{Wu} \mathrm{Li}$, An Kang, Shaanxi Province. The climate is moderate, being north subtropical humid monsoon, and there is abundant rainfall. The mean annual temperature is $15.6^{\circ} \mathrm{C}$, with the mean temperature of the hottest month being $27.5^{\circ} \mathrm{C}$ (July). Based on statistical data of precipitation for An Kang City over the years 1960 - 2008, the mean annual precipitation is $842.1 \mathrm{~mm}$, the maximum annual precipitation is $1157.5 \mathrm{~mm}$, the maximum monthly rainfall is $297 \mathrm{~mm}$, and the maximum daily rainfall is $161.9 \mathrm{~mm}$. The mean annual evaporation capacity is $1408.4 \mathrm{~mm}$, the maximum annual evaporation capacity $1543.5 \mathrm{~mm}$, and the mean annual sunshine is $1662.9 \mathrm{~h}$.

The test site mainly consists of silty clay, gravel and pebbles of the Quaternary Holocene, silty clay and gravel of the Pleistocene and middle Pleistocene, and silty mudstone of the Palaeogene. Alluvial silty clay of the Pleistocene Quaternary is used in the testing. The water content of the soil under natural state is high. The soil appears brown, hard and relatively uniform, including Fe-Mn spots, cinereous plaques and caliche nodules. Joint fissures are more developmental, some of the soil has a clay interlayer and the swelling potential is weak.

\section{Test introduction}

\section{Model box}

The model box faces south and comprises three flanks and an underside (concrete slab). The dimensions of the model box are $510 \mathrm{~cm}$ long by $200 \mathrm{~cm}$ wide and $250 \mathrm{~cm}$ high. One of the flanks contains four $20 \mathrm{~cm} \times 80 \mathrm{~cm}$ and one $80 \mathrm{~cm} \times 100 \mathrm{~cm}$ tempered-glass observation windows. Meanwhile, there are also two free surfaces, that is to say, a top surface and a slope face. A $2 \mathrm{~cm}$-thick cement sand plaster is inside the model box, and it is equably covered in a polyurethane waterproofing coating to prevent the atmosphere from affecting the filling from the flank. In addition, horizontal and vertical steel tubes are used outside the model box to support it, so preventing its lateral deformation. 


\section{Test methods}

Owing to the climatic conditions in An Kang over the years, tests were carried out in June and July. Using local expansive soil as a model for the test (basic engineering properties are shown in Table 1), the degree of compaction is 0.90 (under optimum water content). Construction with a hierarchical approach and slope cutting after completion, resulted in a slope ratio of 1:1.5. The testing of the rainfall system was controlled by artificial rainfall, whereas evaporation was determined by the actual weather situation categorised as cloudy days (neither rain, nor sunshine), and sunny days. The specific conditions are shown in Table 2.

Table 1. Test results of compacted expansive soils (0.90) used in the model test

\begin{tabular}{ccccccccc}
\hline $\begin{array}{c}\text { Dry } \\
\text { density } \\
\left(\mathbf{g} \cdot \mathbf{c m}^{\mathbf{3}}\right)\end{array}$ & $\begin{array}{c}\text { Water } \\
\text { content } \\
(\%)\end{array}$ & $\begin{array}{c}\text { Severe } \\
\left(\mathbf{k N} \cdot \mathbf{m}^{-3}\right)\end{array}$ & $\begin{array}{c}\text { Porosity } \\
\text { ratio }\end{array}$ & $\begin{array}{c}\text { Satura- } \\
\text { tion } \\
(\%)\end{array}$ & $\begin{array}{c}\text { Cohesion } \\
(\mathbf{k P a})\end{array}$ & $\begin{array}{c}\text { Angle of } \\
\text { internal } \\
\text { friction } \\
(\mathbf{0})\end{array}$ & $\begin{array}{c}\text { Average } \\
\text { degree of } \\
\text { free } \\
\text { expansion } \\
(\%)\end{array}$ & Turgidity \\
\hline 1.67 & 13 & 19.8 & 0.499 & 61.2 & 168.0 & 20.5 & 47 & week \\
\hline
\end{tabular}

Table 2. Brief introduction to test method

\begin{tabular}{|c|c|c|c|}
\hline Pilot phase & Test schedule & Precipitation/mm & $\begin{array}{l}\text { The duration of } \\
\text { rainfall/h }\end{array}$ \\
\hline Phase 1 & $\begin{array}{c}\text { Standing after } \\
\text { completion of filling, } \\
\text { clear day accumulated for } \\
\text { five days, overcast day } \\
\text { accumulated for four } \\
\text { days }\end{array}$ & I & I \\
\hline Phase 2 & $\begin{array}{l}\text { The first rainfall, } \\
\text { sunshine a day after the } \\
\text { rain }\end{array}$ & 10.8 & 0.5 \\
\hline Phase 3 & $\begin{array}{l}\text { The second rainfall, } \\
\text { sunshine four days after } \\
\text { the rain }\end{array}$ & 27 & 0.5 \\
\hline Phase 4 & $\begin{array}{l}\text { The third rainfall, } \\
\text { sunshine accumulated for } \\
\text { nine days, overcast day } \\
\text { accumulated for four } \\
\text { days }\end{array}$ & 45.1 & 1 \\
\hline Phase 5 & $\begin{array}{l}\text { The fourth rainfall, } \\
\text { overcast day accumulated } \\
\text { for twelve days }\end{array}$ & 45.1 & 1.5 \\
\hline
\end{tabular}

\section{Observation instruments and methods}

In order to comprehensively analyse the effects of slope deformation caused by rainfall and evaporation, using a variety of test tools and methods to monitor the slope deformation, water content of the surface soil and changes in rainfall and evaporation, the specific programmes were as follows. 
Using the drying method and TDR (Time Domain Reflectometry) soil moisture sensors to test the water content of the soil

The TDR soil moisture sensors were the FDS-100 made by Qing Sheng Electronic Technology Company. They were placed in three sections at the top, middle and toe of the slope position, respectively at depths of $10 \mathrm{~cm}, 30 \mathrm{~cm}, 80 \mathrm{~cm}$ and $160 \mathrm{~cm}$ from the slope surface. Since the TDR tests the volumetric water content of the soil and errors exist between the measured value and the actual water content of the soil and there is still some instability when using the empirical formula to transform the results into the mass water content, for the sake of accurate measurements, the drying method was used to calibrate samples. Then the relationship between the output signal and the water content of the soil was directly established. In the monitoring process, employing a removable TDR attached to the slope surface, the water content of the soil mass within the range of $0 \sim 5 \mathrm{~cm}$ of the surface at any time can be tested.

Measuring the expansion and shrinkage deformation of the slope soil surface with Hall displacement sensors

Considering the test soil is weakly expansive soil, the swell - shrink deformation of the soil is low and accurate measurements with conventional methods cannot be achieved. Therefore, the principle of the Hall-effect self-producing displacement sensors was used to measure soil micro-deformation with accuracy of up to $0.1 \mathrm{~mm}$ and a range of $0 \sim 5 \mathrm{~cm}$. In addition, it can measure displacement change in any direction, and using mathematical methods, it can transform the test signal into vertical and horizontal displacement components. Displacement sensors were arranged on the slope crest, the slope centre, and the slope base, respectively, and the burial depth for the surface sensors was $5 \mathrm{~cm}, 10 \mathrm{~cm}$ and $30 \mathrm{~cm}$. The burial depth of the slope crest sensor was $160 \mathrm{~cm}$.

\section{Testing method for rainfall, soil evaporation and temperature, relative humidity}

Rainfall was realized by a designed simulation system of spraying artificial rain during the test. The system was supplied by a self-priming water pump which delivers water by a water main supply pipe. Rainfall was simulated using a 14 PVC sprinkler pipe. A high-precision flow meter was installed on the main supply pipe and a control valve was used to control the flow and so achieve the purpose of controlling the rainfall. To record runoff, a water-collecting well was dug in the delivery port of the slope base, and the volumetric method was used to measure the volume of runoff from the slope surface during rainfall. The method recommended in the literature (Feng, 1988) to assess soil evaporation is to calculate the volumetric water content. Changes in atmospheric temperature and relative humidity were recorded by the German DCF-77 barometer in real time.

For all the above instruments, the test data of TDR and the displacement sensor are from the high-precision data acquisition unit of the Hydra series of the Fluke Corporation in the United States, but the barometer levels, volume of runoff and so on need manual reading and recording. The arrangement of the components of each group is shown in Fig. 1. 

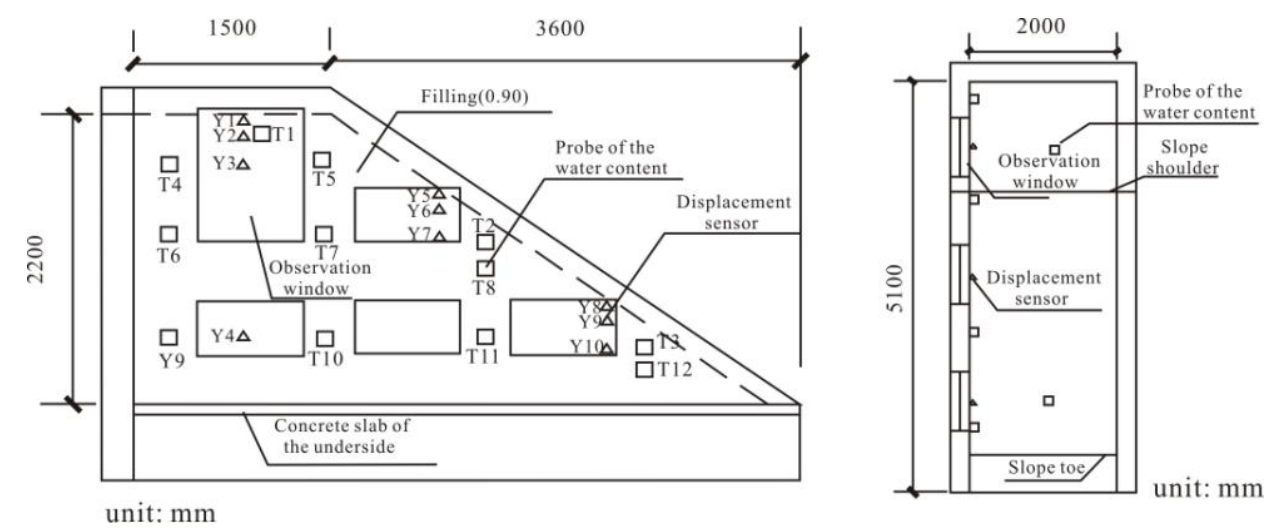

Figure 1. Schematic diagram of layout of the components

\section{Analysis of results of field test}

During the months of monitoring, conducting a total of four artificial rainfall simulation experiments (Table 2), the rainfall incidents were all at 11am. The climatic conditions were sunshine on the first three occasions, and cloudy on the fourth. Before the rainfall, in order to maintain the self-balancing between the model and the various sensors, the first phase of the test was set as standing. After the test started, a cloth was fixed behind the model to cover it completely to prevent natural rainfall infiltration disturbing the tests, therefore, the tests began under relatively dry conditions.

\section{Analysis of change of air temperature and relative humidity}

According to the atmospheric temperature and humidity data recorded in real time (show in Fig. 2), the atmospheric temperature of the test ranges from 20.3 to $37.9^{\circ} \mathrm{C}$, the maximum of the average temperature is $33.7^{\circ} \mathrm{C}$; the minimum is $21^{\circ} \mathrm{C}$. Relative humidity ranges from $31 \%$ to $98 \%$, the maximum of the average humidity is $90 \%$, the minimum is $37 \%$. After comparing the two, it was found that there is an inverse correlation between them; the relative humidity is lower when the temperatures are higher. After the start of the test, the temperatures showed an upward trend; with the rainy season coming in July, the temperature began to drop; the higher temperatures and the lower relative humidity were concentrated in late June.

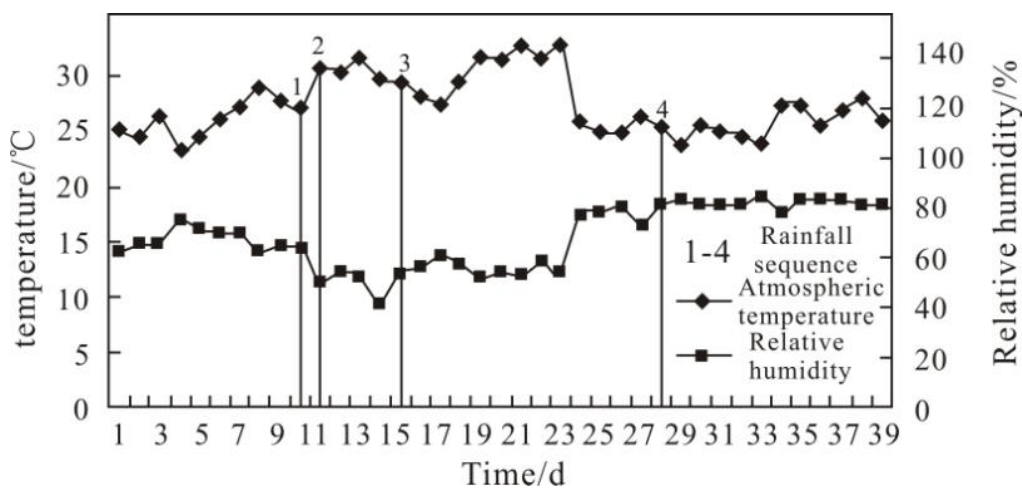

Figure 2. Change of daily mean atmospheric temperature and relative humidity during the experiment 


\section{Analysis of water content}

Fig. 3 is the response curve between the water content of the slope surface soil ranging from $0 \mathrm{~cm}$ to $5 \mathrm{~cm}$, soil evaporation, and the rainfall and evaporation effect. As can be seen, the change in the water content is consistent with evaporation. At the beginning of the test, during the 9 days standing, the water content decreased from an initial $12.4 \%$ to $9.5 \%$, but soil evaporation was basically maintained at $1 \mathrm{~mm} / \mathrm{d}$. Both of the changes in these two units were smaller. In the course of the four rainfall incidents, the water content rapidly increased in the preliminary rainfall, and was maintained at about $18 \%$. Meanwhile, the rainfall evaporation appeared higher peak on the first three rainfall incidents, and they were $3.1 \mathrm{~mm} / \mathrm{d}, 4.2 \mathrm{~mm} / \mathrm{d}$ and $3.9 \mathrm{~mm} / \mathrm{d}$, respectively. What is more, the peaks for the water content and evaporation appeared at the same time. After the first three rainfall incidents, both rapidly decreased at the same time, until levelling off. The three phases are a constant rate phase (a steep curve), a deceleration phase (a decrease in steepness becoming gentle) and a residual stable phase (a flat section). So there is interplay between the water content and evaporation, and the water content is reduced by controlling the evaporation, while at the same time affecting the level of evaporation.

Compared with the first three rainfall incidents, the soil evaporation was still smaller after the fourth incident, the water content slowly decreased. By comparing the climatic conditions after the rainfall incidents, the reason was easily found. After the first three incidents, the surface of the soil was subjected to direct solar radiation; the temperature was higher, so providing enough heat for evaporation. The relative humidity was lower; the water vapour pressure gradient between the surface and the atmosphere caused the evaporation capacity to increase. However, there was cloud after the fourth rainfall incident, the temperature was lower and the relative humidity was higher, so the evaporation capacity was lower. Moreover, from the perspective of agricultural science, with rain, the water content increases; as well as capillary action with water flowing up and down, gravity also affects water, and if there is enough moisture on the surface it gasifies. The water content reduces with evaporation consuming the water; soil moisture gradually reduces forming a film of water. While the water content continues to reduce, the soil can only transport water with the help of the film of water and water vapour. Therefore, with evaporation continuing, the rate of evaporation gradually decreases.

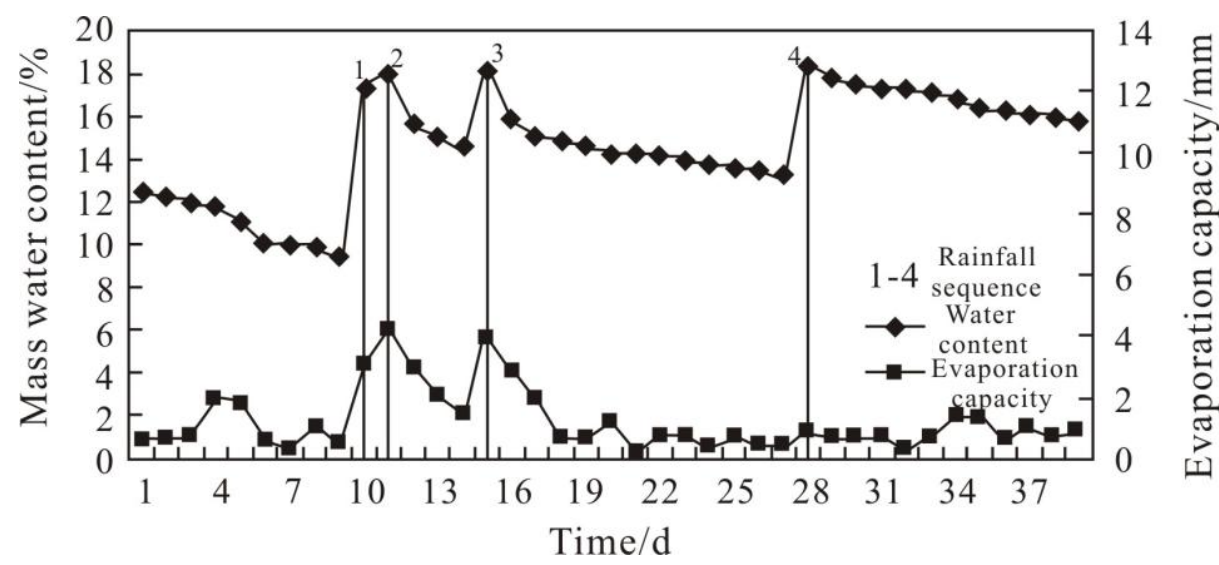

Figure 3. Evaporation capacity and the response curves of moisture content in the range of $0 \sim 5 \mathrm{~cm}$ 
Figs. 4-5 show the response curves of the water content in different slope positions at depths of $10 \mathrm{~cm}$ and $30 \mathrm{~cm}$, respectively. As can be seen from the figures, there are different levels of impact on the water content at different places and depths under the effects of the rainfall and evaporation. At the $10 \mathrm{~cm}$ location, the water content of the slope crest and the slope base increases after the fourth rainfall incident, but only if the slope centre increases after the third incident. At the $30 \mathrm{~cm}$ location, the water content of the slope crest increases after the third incident, and that of the slope base increased after the fourth incident, but only if the slope centre did not change. On this basis the following law can be stated: the depth of rainfall penetration continually increases with increasing rainfall and rainfall duration. In addition, the depth of rainfall penetration is different in different places on the slope; the depth of rainfall penetration in the slope crest is the greatest, followed by the base, and it is the lowest at the slope centre. In contrast to changes in the water content along the depth (Figs. 3-6), the most significant effect arising from the rainfall on the slope surface ranges from $0 \mathrm{~cm}$ to $5 \mathrm{~cm}$ and the range is also the greatest. With increasing depth, the range of the water content drastically reduced (shown in Fig. 6). It also shows that evaporation drastically reduces with increasing depth. In brief, the changes in the water content are not only controlled by rainfall and rainfall duration, but also controlled by the initial soil water content, for example, the increasing range of the water content after the first rainfall is much greater than that after the second rainfall.

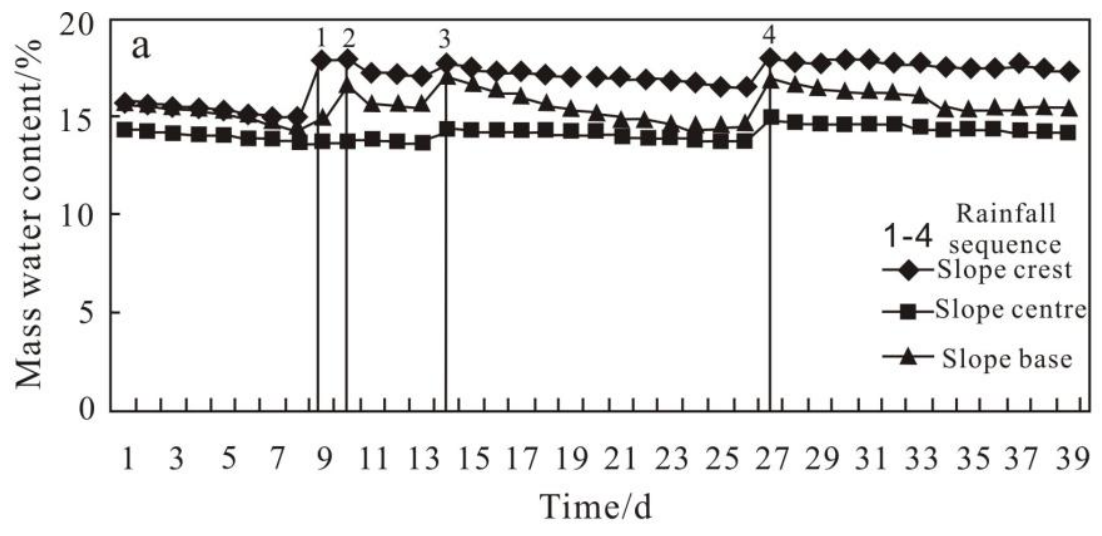

Figure 4. Response curves of moisture content in a depth of $30 \mathrm{~cm}$

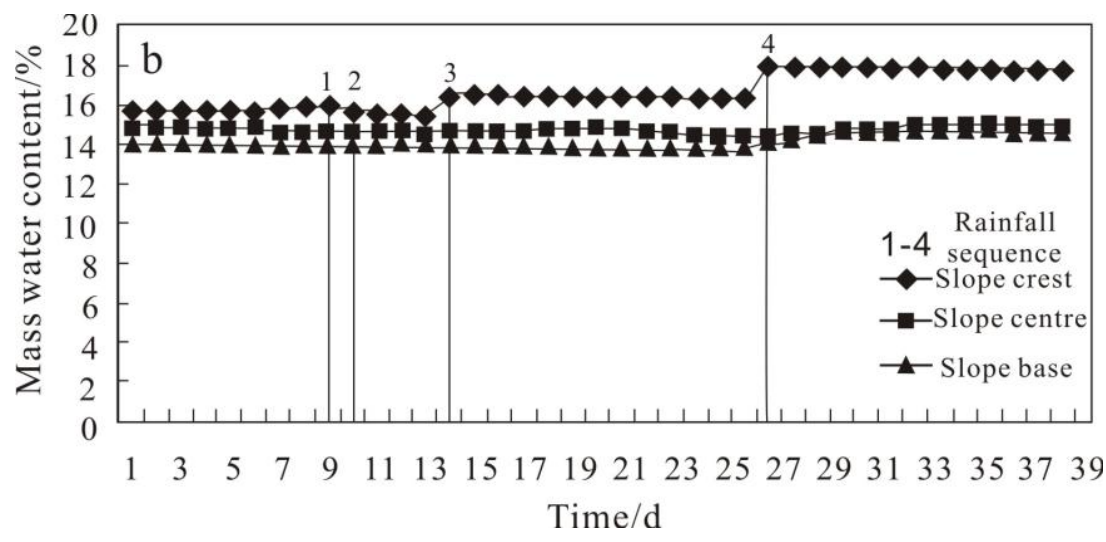

Figure 5. Response curves of moisture content in a depth of $10 \mathrm{~cm}$ 


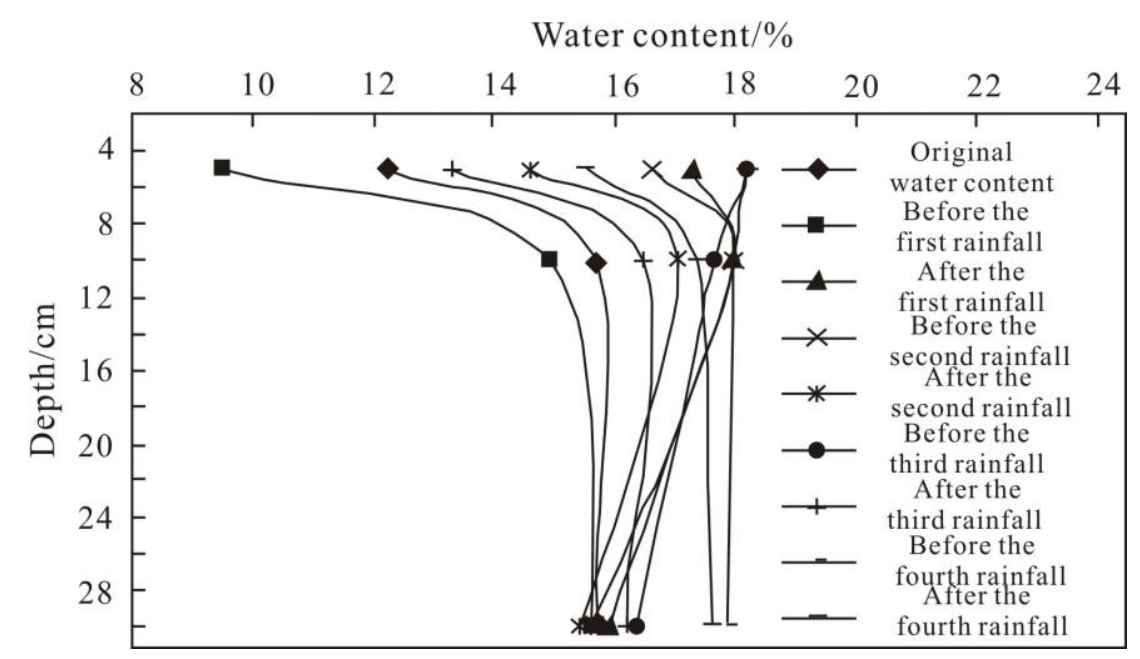

Figure 6. The response of moisture content in depth profile of slope top

In summary, during the monitoring period, the changes in the soil water content are mainly concentrated in the slope surface confined to $20 \mathrm{~cm}$, and the scope is narrower. The reason relates to the permeability of, rainfall on and rainfall duration over the consolidated expansive soil. The permeability of the complete expansive soil is minimal. When rain falls, fissures in the expansive soil allow rainwater to quickly penetrate the surface of the soil, but the soil body swells after the water absorption, and then cracks quickly close (shown in Figure 7), the permeability of the soil drastically reduces and the surface runoff begins to increase rapidly. Only a small part of the rainwater infiltrates into the soil. In addition, the compactness of the expansive soil is high after it is tamped (the expansion coefficient is small), and if the rainfall duration is short (the longest duration in this test was $1.5 \mathrm{~h}$ ), there is insufficient time for slow infiltration of the rainwater. Therefore, in this rainfall simulation, in which the intensity is high but the duration is short, the variation range of the slope's water content is small. Presumably, when the amount of rainfall is the same, but the rainfall intensity is low and the duration is long, the infiltration depth will be greater.
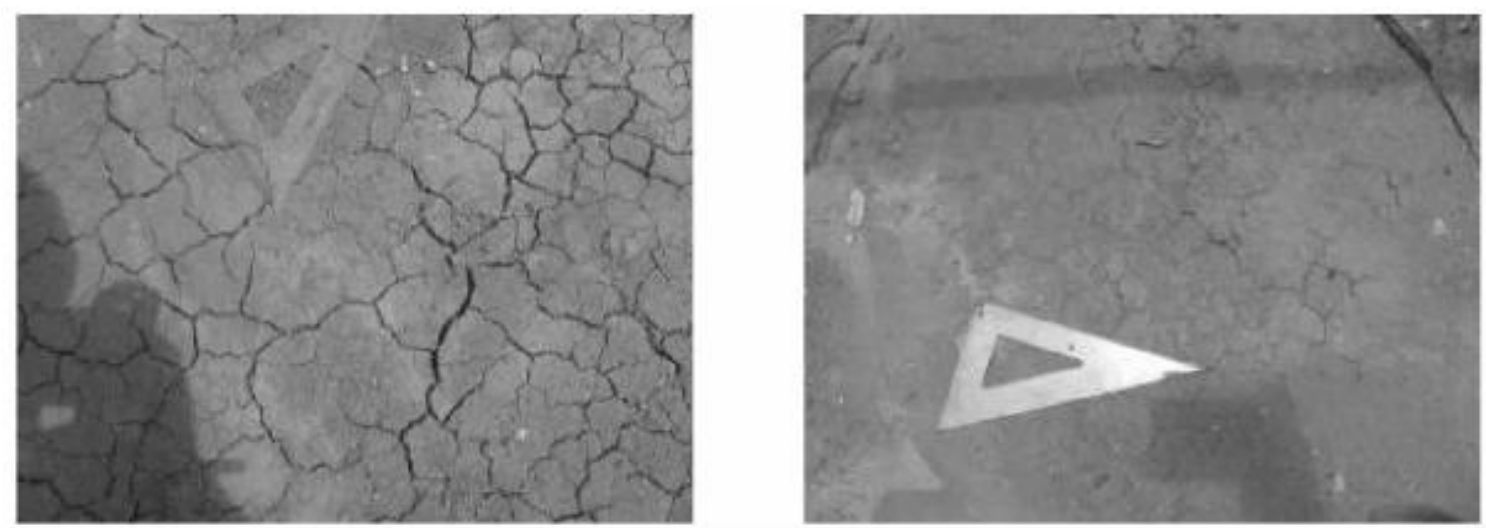

Figure 7. Surface crack closure after heavy rainfall 


\section{Analysis of slope deformation}

Slope deformation occurs in the horizontal and vertical directions. If the direction of horizontal deformation is along the slope, settlement is down, called positive, otherwise they are negative. During the test, it has been found that the change in water content is closely related to rainfall infiltration and atmospheric evaporation. The incidence of the water content at different points on the slope differs. The swell - shrink deformation of the expansive soil is directly controlled by the water content. Therefore, displacement at different points on the slope is different, specifically as follows.

\section{Horizontal slope deformation under the rainfall-evaporation cycle}

This section only gives the response curve between the horizontal displacement at the representative place at the slope's base and rainfall - evaporation (see Figure 8). As can be seen from the figure, the change at the slope base during the standing phase is small, at the $5 \mathrm{~cm}$ and $10 \mathrm{~cm}$ points generating outward deformation of only $1.7 \mathrm{~mm}$ and $0.6 \mathrm{~mm}$. In the first rainfall incident, the horizontal deformation rate at the $5 \mathrm{~cm}$ point reached its maximum during the monitoring period at $2.7 \mathrm{~mm} / \mathrm{d}$. After the third incident, the horizontal displacement continually rose, but the rate decreased with the increase in the number of rainfall incidents (shown in Figure 9). Overall, in the rainfall process, the water content increases in a range of shallow soils, and water absorption of the expansive soil leads to expansion, all resulting in the horizontal deformation in the slope base sharply rising. In the evaporation process after the rainfall, the deformation is moderate and low. Horizontal displacement, along with the change law of the depth, displays that horizontal deformation decreases rapidly with the increasing depth; this point agrees with the change law of the water content discussed earlier. At the $30 \mathrm{~cm}$ point, in particular, the horizontal form is basically unchanged. In this test, different levels of deformation at the different points in descending order were: the slope base, the slope centre and the slope crest.

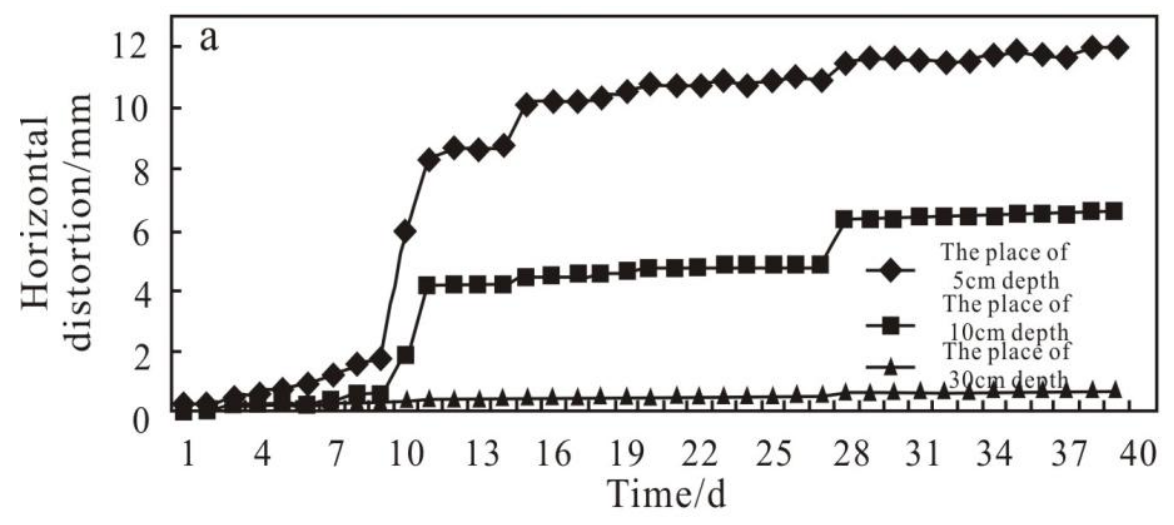

Figure 8. Horizontal deformation in depth profile at toe of slope

\section{Vertical slope deformation under the rainfall-evaporation cycles}

Vertical slope deformation under the rainfall - evaporation cycle mainly reflects the swell-shrink deformation in the slope crest (Fig. 10). As shown in the figure, during the standing period, the slope crest, under the effects of self-weight and drying 
shrinkage, shows lower settlement deformation. After the first rainfall, due to the lower initial water content, the change in the water content of the surface soil at the $5 \mathrm{~cm}$ and $10 \mathrm{~cm}$ points is greater after absorption, generating greater expansive deformation with rates of $1.6 \mathrm{~mm} / \mathrm{d}, 1.03 \mathrm{~mm} / \mathrm{d}$, respectively (see Fig. 11 ). In the second rainfall incident, because the soil has not desiccated and the initial water content is high, the upward expansive deformation is small, mainly caused by swelling due to rainwater infiltrating into the deeper soil. After four days of sunshine, the surface soil shrinks from drying, resulting in a downward settlement. With the advent of the third rainfall incident, the surface soil continues to bulge with drying shrinkage occurring after evaporation, and the cycle is repeated. Eventually, the cumulative amount of deformation in the slope crest $(1.9 \mathrm{~mm})$ is less than the cumulative amount of the horizontal deformation in the slope base $(12 \mathrm{~mm})$.

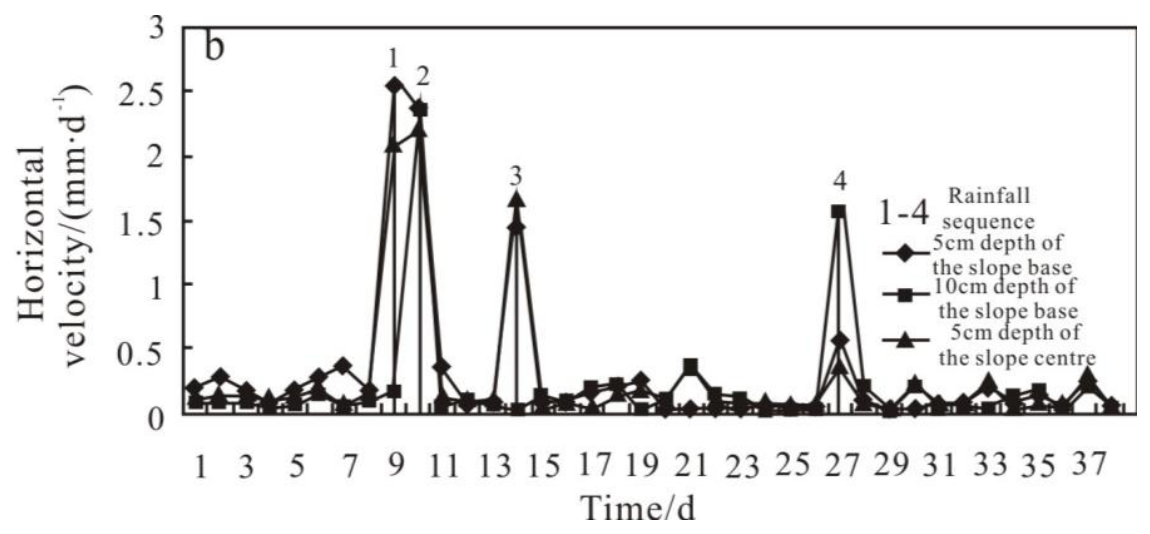

Figure 9. Vertical deformation in depth profile at top of slope

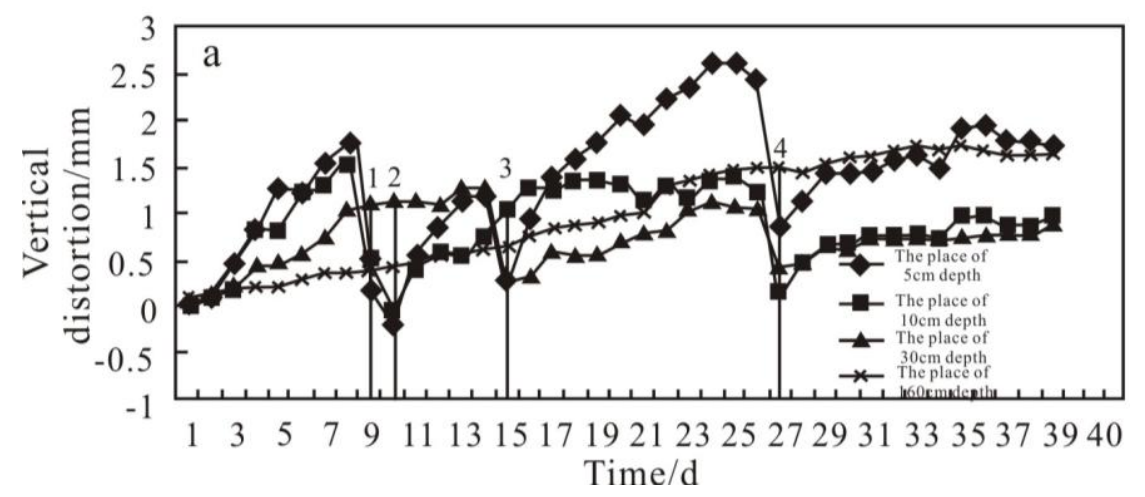

Figure 10. Horizontal deformation rate at different position of slope

Compared with the changed features in the swell-shrink deformation with depth (Fig. 9) and the number of the rainfall incidents (Fig. 11), it can be shown that the laws of vertical and horizontal deformation at this point are basically the same: with increasing depth and the number of rainfall incidents, the deformation rate constantly decreases. However, expansion after the fourth rainfall incident is higher than that after the third. Combined with the changes in the water content during this period, it is thought that, before rainfall, the soil water content decreased by long-running evaporation, and if the 
initial water content was lower when rain fell, then it had greater expansive potential; in addition, the depth of rainwater infiltration is greater (more than $30 \mathrm{~cm}$ ), the lower the soil thickness participating in the greater expansive deformation; the accumulative deformation at the top surface is higher than that of the third incident. Therefore, the amount of deformation not only depends on the depth of rainwater infiltration, but also relates to the initial water content.

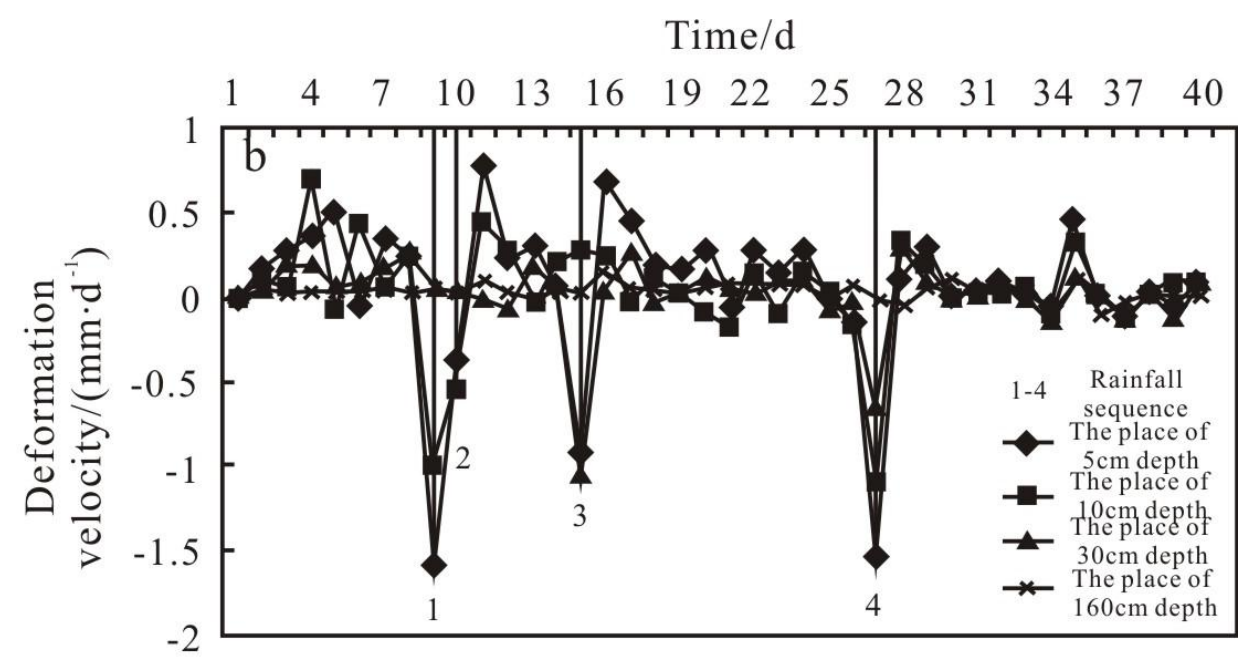

Figure 11. Vertical deformation rate in depth profile of slope top

Compared with the deformation law of the horizontal slope, it can be shown that vertical deformation mainly reflects the swell-shrink deformation in the slope crest; deformation on the surface is mainly horizontal deformation, and vertical deformation is rare. Deformation on the slope surface is significantly higher than that in the slope crest. The reason is that under the effect of rainfall, the soil water content increases and it is bound to generate expansive deformation. If this is not restrained, expansive deformation is the same in all directions. In the vertical direction, expansion of the soil is controlled by the self-weight of the overlying soil, and the greater the depth, the stronger the constraints; while the constraints of the surface soil perpendicular to the slope direction are few. Combined with the downhill scouring force produced by runoff movement, the deformation on the slope surface is mainly horizontal deformation under the effect of expansibility and the resultant force of runoff.

\section{Analysis of the characteristics and genetic mechanism for the filling slope deformation}

\section{Characteristics of slope deformation}

Contrasting the deformable features of various parts of the slope mainly shows vertical swell-shrink deformation in the slope crest, but horizontal accumulative deformation in the slope surface. The deformation in the slope surface is greater than that in the slope crest. With increasing depth and the number of rainfall incidents, the rate of the slope deformation drastically reduces. Under the rainfall-evaporation effect, the results of each cycle will generate outward accumulative deformation in the slope. Presumably, with the 
number of rainfall-evaporation cycles increasing, the long-term accumulation of surface accumulative deformation may cause tension cracks in the slope shoulder and shear stress concentration to form in the slope base. Along with the influence of runoff on the scouring and erosion of the slope and the form of the slope surface changing, it will cause progressive accumulation damage to the filling slope surface.

For a completely uniform filling slope, there are fundamental differences between the hydrogeological environment and the natural, and no fractures. Furthermore, the leading factor in generating and developing the filling slope deformation is the swell-shrink deformation. The swell-shrink deformation is closely related to changes in the water content; rainfall determines the degree of humidity and the depth of infiltration, and it is the main factor leading to the sharp rise in slope deformation. On the contrary, evaporation promotes water loss and fractures develop; the intensity determines the degree of desiccation with the level of the initial water content being one of the prerequisites determining the infiltration of rainwater and the swell-shrink deformation. Therefore, the deformation of the filling slope and rainfall-evaporation cycle are closely related.

\section{Analysis of the mechanism of the slope deformation under the rainfall-evaporation effect}

\section{Swell-shrink mechanism of the expansive soil}

Many scholars have proposed a variety of theories to explain the swell-shrink mechanism of expansive soil (Hao and Zhu, 1999, Tan and Kong, 2001). For expansion of such soil caused by swelling, the water molecules constantly envelop a crystal layer, soil particles and their aggregate, and through the complex physical and chemical effects transform this process into its mechanical effect, and then connect to each other forming adsorbed water. The adsorbed water consists not only of the electrostatic attraction of the clay mineral due to lattice replacement, but also of the concentration gradient between the inter-granular water and the external soaking water because of the different concentration, that is to say, seepage pressure, and the matrix suction potential, etc. Under the effect of the various forces, the combined water film constantly thickens until the thickness reaches a critical value, achieving homeostasis. Due to the combined water film thickening, and the distances among the crystal layers and the crystalline grains increasing, at last the soil volume expands; conversely, when the water film becomes thin or disappears, the distances among the crystalline grains decrease and the soil volume is reduced accordingly. However, the swell-shrink mechanism of the expansive soil dose not entirely depend on the material composition of the expansive soil, but also depends on the space microstructure of these substances; it is a space condition that forms the swell-shrink deformatio (Li et al., 2007).

\section{Swell-shrink deformation of soil under rainfall}

The laws of rainwater infiltration during the test show that the rainfall and infiltration process of the expansive soil slope is broadly divided into three stages in the lower water content of the surface soil. 1) The free infiltration stage, in the early rainfall is due to the greater gradient of the surface water content, coupled with cracks generated by the drying shrinkage of the expansive soil; rainwater quickly penetrates the soil, and the infiltration is greater as surface runoff generally does not occur at this time. 2) The scouring infiltration stage occurs after the water content of the slope surface quickly reaches a stable value. The cracks close, the permeability coefficient sharply decreases 
and the infiltration capacity is significantly reduced. At the same time, the surface runoff rapidly increases, the surface soil tardily reaches ponding infiltration conditions under the effect of erosion, and the ponding continues to deepen. 3) The steady infiltration stage occurs when, with continued rainfall, the infiltration gradually stabilizes and the rate of rainwater infiltration reaches the lowest value. In this test, due to the lower permeability coefficient, and the heavier rainfall, most of the rainwater infiltration process is in the scouring infiltration stage.

In the infiltration process, the soil water content increases, leading to the distances among the crystal layers and crystalline grains increasing, and then generating swell-shrink deformation. If not restrained, the swelling deformations are the same in all directions. At the free infiltration stage, because of cracks in the slope surface, the slope crest and base, the constraints on the parallel surface in the slope crest and base are at a minimum, therefore, at this stage there is mainly swell-shrink deformation of the parallel surface; cracks continually gather together and close. At the scouring infiltration stage, due to the cracks closing, the constraints on the parallel surface in the slope crest and base increase. The constraint perpendicular to the slope direction is the lower, combined with the runoff in the downward slope generating erosion force. Therefore, the deformation on the slope surface is mainly horizontal deformation under the effect of the expansible and resultant force of runoff. While the soil of the slope crest swells is controlled by the self-weight of the soil layers, the horizontal deformation is greater than that of the vertical deformation. At the steady infiltration stage, the expansive deformation of the upper soil is completed; the expansion of the lower soil is more controlled by the soil self-weight and monolithic deformation is not obvious.

\section{Soil shrinkage cracking under evaporation}

From the previous analysis, it can be seen that when there are the vapour pressure gradient between the Earth's surface and the atmosphere, and enough heat required evaporating rainfall, evaporation capacity of soil after rainfall has gone through constant rate-deceleration rate-residual stable three stages. At different stages of the evaporation, the soil moisture is not only different physically but also quantitatively.

With the gradual loss of moisture in evaporation and the bound water within the crystallization layer, the crystalline grain becomes thin, and the soil turns to non-saturated from saturated, leading to the generation of suction which continues to increase. Under the effect of suction, the soil grains continuously gather together and arrange, the void ratio becomes small; the volume of the soil shrinks. Since the suction forms a tensile stress field in the soil, when the tensile stress among the soil grains is greater than the strength of the extension among the soil grains, cracks will be produced. In fact, the shrinkage of the soil consists of two parts: transverse shrinkage and vertical shrinkage. In most cases there are anisotropic characteristics (Bronswijk, 1988), but these two show different forms. The results of the soil transverse shrinkage are cracking of the slope surface, and the results of the vertical shrinkage are land subsidence. In this test, cracks generated by the transverse shrinkage are in the slope crest and surface, but land subsidence caused by the vertical shrinkage is mainly in the slope crest.

In summary, the essential reason for the deformation phenomenon of the expansive soil slope is its own special material composition and structural characteristics. Changes in soil humidity under the rainfall-evaporation effect are due directly to external factors resulting in slope deformation. Therefore, the mechanism of the expansive soil slope deformation is the result of interplay between its internal and external conditions. 


\section{Conclusions}

(1) The rainwater infiltration process in the new fill slope includes free infiltration, scouring infiltration and stable infiltration. In this test, due to the greater rainfall intensity, the permeability of consolidated expansive soil drastically reduced after the cracks had closed and the surface runoff began to increase rapidly, giving rise to only minor rainwater infiltration into the soil. All these led to the rainwater infiltration process, mainly in the scouring infiltration phase, resulting in the limited depth of infiltration.

(2) When there are the vapour pressure gradient between the Earth's surface and the atmosphere and enough heat for evaporation, the level of water content is important and affects soil evaporation. The water content and evaporation affect each other, and their changing process can be divided into three stages: constant, rate-deceleration and stable rate-residual.

(3) For a completely uniform filling slope, the leading role of the development of the deformation is the expansion of the soil. It mainly shows vertical swell - shrink deformation in the slope crest, but horizontal accumulative deformation in the slope surface. With increasing depth and the number of rainfall incidents, the rate of slope deformation drastically reduces.

(4) The deformation of the filling slope is closely related to the rainfall - evaporation effect, and rainfall is the main factor leading to the slope deformation sharply rising; evaporation is a necessary prerequisite for the development of the deformation.

(5) With the number of rainfall-evaporation cycles increasing, the long-term accumulation of surface accumulative deformation may cause tension cracks in the slope shoulder, and shear stress concentration in the slope base. Along with the influence of the runoff on the scouring and erosion of the slope and the form of the slope surface changing, this will cause progressive accumulation damage to the filling slope surface.

(6) The essential reason for the deformation phenomenon of the expansive soil slope is its own special material composition and structural characteristics. Changes in soil humidity under the rainfall - evaporation effect are direct external factors resulting in slope deformation. Therefore, the mechanism of the expansive soil slope deformation is the result of interplay between its internal and external conditions.

(7) Considering all of the above factors, it is considered that preventing the deformation of the expansive soil filling slope in the rainfall-evaporation cycle is affected by both. First, the cycle effectively reduces the change in soil humidity in the range of influence of the slope surface and second, it prevents the influence of runoff on the scouring and erosion of the slope.

Acknowledgements. The paper is mainly funded by the the State Key Program of National Natural Science of China (41630639) and National Natural Science Foundation of China (41372269) and the State Key Laboratory of Continental Dynamics Foundation (2016). Herein, I express my deepest gratitude to them and those who have gave me further help during the completion of this paper.

\section{REFERENCES}

[1] Bronswijk, J. J. B. (1988): Modeling of water balance, cracking and subsidence of clay soils. - J Hydrol (Amsterdam) 97: 199-212. 
[2] Chen, J. B., Kong, L. W., Guo, A. G., et al. (2007a): Deformation characteristics of expansive soil slopes under precipitation and evaporation. - China Civil Engineering Journal 40(11): 70-77. (in Chinese)

[3] Chen, S. S., Zheng, C. F., Wang, G. L. (2007b): Researches on long-term strength deformation characteristics and stability of expansive soil slopes. - Chinese Journal of Geotechnical Engineering 29(6): 795-799. (in Chinese)

[4] Ding, J. M.,Wang, Y. H.,Chen, Z. Y. (2006): Water-destroyed disaster of expansive soil roadbed and it's forecast based on rough neural network. - Journal of Natural Disasters 15(6): 168-173. (in Chinese)

[5] Feng, C. H. (1988): The determination of soil moisture zero-flux plane and calculation of soil evaporation. - Chinese Journal of Soil Science 2: 71-73. (in Chinese)

[6] Hao, Y. Q., Zhu, J. Q. (1999): Theoriesand analysis about expensive soil deformation of swelling and shrinking. - Bulletin of Soil and Water Conservation 19(6): 58-61. (in Chinese)

[7] Li, Z. Q., Yu, W. L., Fu, L., et al. (2007): Research on expansion and contraction rules and disaster mechanism of expansive soil. - Rock and Soil Mechanics 40(11): 70-77. (in Chinese)

[8] Ng, C. W. W., Zhan, L. T., Bao, C. G., et al. (2003): Performance of an unsaturated expansive soil slope subjected to artificial rainfall infiltration. - Geotechnique 53(2): 143-157.

[9] Sammori, T., Tsuboyama, Y. (1991): Paramtric study on slope stability with numerical simulation in consideration of seepage process. - In: Beled. Proc. 6th Symp. on Landslides. Rotterdam: A. A. Balkema 539-544.

[10] Tan, L. R., Kong, L. W. (2001): The swelling and contractionrule of montmorillonite crystal and its relation with the adsorption ability of montmorillonite interlayer. - Science in China (Series D) 31(2): 119-126. ( in Chinese)

[11] Toll, D. G. (2001): Rainfall-induced landslidesin Singapore. - Proceedings of the institution of civil engineers-geotechnical engineering 149(4): 211-216.

[12] Tu, X. B., Kwong, A. K. L., Dai, F. C., et al. (2009): Field monitoring of rainfall infiltration in a loess slope and analysis of failure mechanism of rainfall induced landslides. - Engineering Geology 105(1-2): 134-150.

[13] Yang, G. L., Ding, J. M. (2006): Model teston expansion and shrinkage deformation inexpansive soil roadbed. - China Journal of Highway and Transport 19(4): 23-29. (in Chinese)

[14] Yuang, C. H., Zhou, J., Yang, M. L. (2007): Treatment of expansive soil slopes beside highways. - Chinese Journal of Rock Mechanics and Engineering 26(Z1): 3073-3078. (in Chinese)

[15] Zhang, Y. Y., Hu, X. W., Zhu, H. Y. (2007): Prospect of reseach on relationship between landslide and rainfall. - Journal of Natural Disasters 16(1): 104-108. (in Chinese) 